\title{
Digital Experience: How to Find a Tool for Evaluating Business Economic Risk
}

\author{
Igor Lyukevich ${ }^{1 *}$, Anton Agranov², Nadezhda Lvova ${ }^{3}$, Liudmila Guzikova1 \\ ${ }^{1}$ Graduate School of Industrial Economics, Institute of Industrial Management, Economics and Trade, Pe-ter \\ the Great St. Petersburg Polytechnic University, Politechnicheskaya St., 29, St. Petersburg, 195251, Russia \\ ${ }^{2}$ The Faculty of Part-Time Studies Emperor Alexander I St.Petersburg State Transport University, Moskov- \\ sky pr., 9, 190031, Russia \\ ${ }^{3}$ Department of Theory of Credit and Financial Management St.Petersburg State University, Saint- \\ Petersburg, Universitetskaya nab., 7/9, 199034, Russia
}

\begin{abstract}
Risk evaluation includes not only quantitative or qualitative assessment but the choice of action that depends on the risk event. The paper highlights key research in the field of risk assessment from 1921 to the present day. The suggested concept of business eco-nomic risk evaluation is substantiated using the criterion of information accessibility. One group of assessment techniques is based on statistical analysis, namely insolvency risk assessment models combined with a group of probabilistic ones. The alternative group includes all techniques that differ from the accumulated data analysis (STAR - Strategic Technology Assessment Review, HAZOP Hazard and Operability Study, and FMEA Fail-ure Mode and Effects Analysis qualitative assessments). Scenario, list, and analogies techniques (SWIFT Structured What If Technique, HACCP Hazard Analysis and Critical Control Points, RCA Root Cause Analysis, BOWTIE, WCS Worst Case Scenario) are more accurately characterized as an evaluation of conditions and consequences of eco-nomic risks. Based on the advantages and disadvantages of risk assessment techniques, this study proposed a classification of the tools for evaluating business economic risk and an algorithm for choosing a tool appropriate for the situation based on the available information. The possibility and directions of practical implementation, as well as the ex-isting digital assessment tool products, are shown.
\end{abstract}

Keywords: Digital experience; Economic risk; Evaluation tool; Qualitative risk assessment; Quantitative risk assessment

\section{Introduction}

Scientific research into the phenomenon of economic risks dates back to the early 20th century. Knight was the first who suggested delineating risk and uncertainty when characterizing probabilistic events in the economic field (Knight, 1921). The next significant work was the study on risk assessment by Neumann and Morgenstern (1944). Formation of adverse outcomes assessment and management science took place in 1950-1990s. Arrow (Nobel Laureate) substantiated the impossibility of describing all risk

\footnotetext{
${ }^{*}$ Corresponding author's email: lyukevich_in@spbstu.ru, Tel.: +7-905-2038110;
}

doi: 10.14716/ijtech.v11i6.4466 
options and showed that the best way to prepare for the onset of the risk event was to assess the consequences of its occurrence and the costs of eliminating them (Arrow, 1951). He also proved the theorem (Arrow's paradox) on the lack of techniques for combining individual preferences for three or more alternatives, which would satisfy some completely fair conditions and always gave a logically non-contradictory outcome (Arrow, 1951). Snider formulated the 'risk management' theory in 1955-1956 (Snider, 1991), and Gallagher gave a description of the risk manager profession (Gallagher, 1956).

With the abolition of the Bretton Woods system of fixed exchange rates, the area of assessing and hedging risks in financial markets evolved. The works of Merton (1973), as well as Black and Scholes (1973), are seen as the key ones. In 1973, the Geneva Association, which united research in the field of risk economics and risk insurance, was established. In the 1990s, risk management obtained the status of the strategic management paradigm. The concept of the internal risk control necessity was finally formed (COSO, 1992). In the 2010s, debates on the innovation risk assessment system started (Nikolova et al., 2017). In this case, risk minimization directions depended on whether it was relat-ed to the high- or low-tech sector (Rodionov et al., 2018). However, risk management in modern finance is one of the fastest growing but actively criticized areas. In particular, Taleb's black swan theory vigorously and flatly criticized the practice of financial and economic decisions based on the assumption that risk prevails over uncertainty (Taleb, 2007). Besides, risk assumption is currently prevailing in business management, which defined the perspective of this study.

In case of an unfavorable event, the decision is either to accept the consequences drawing on reserves or to take preventive actions. Thus, business is likely to incur costs either after or before the risk event. At the same time, due to the apparent transformation of all areas of the economy, 'classical' techniques, tools, and criteria are losing their practical significance, and their actualization is necessary with allowance for the processes of digitalization of the economy (Malevskaia-Malevich et al., 2018).

Available estimates suggest that the quality of products increase when a business risk management system is implemented (Hidayatno et al., 2015; Pariaman et al., 2017). It was shown that with a quality increase, the demand curve, in terms of the quantity of the product/product price, shifts to the right, parallel to itself (Demidenko et al., 2017). Efficiency rates are starting to grow. Owners pay more attention to cash flow and real profits than to accounting (Dvas et al., 2018).

Risk research theory and practice have developed a wide variety of approaches, techniques, and models based on both the quantitative and qualitative analysis of business economic risk factors (Gissel et al., 2007). Apart from this, a comprehensive view of the tools and techniques of risk assessment and features of their application have not yet been proposed. Additionally, the problem of finding and choosing a tool that draws a conclusion on the level of business economic risk has not been fully resolved. Risk assessment should not involve economically impractical periods of time and other costs, and conclusions should be properly substantiated.

We assumed that evaluating business economic risk suggests a special methodical toolkit aimed at quantitative or qualitative assessment of this risk, as well as at the choice of one of the alternative options for actions involving the onset of the risk event. The research hypothesis implies that as part of the existing approaches to assessing business economic risks, it is possible to formulate a search algorithm to find the optimal tool to evaluate economic risk, including digital skills use.

\section{Methods}

The research methodology appealed to a systematic approach. Thus, the research results and conclusions addressed the systematization of business economic risk 
assessment methods and models. To do this, the authors' concept of assessing the corresponding risk was introduced, based on the criterion of information accessibility (Figure 1).
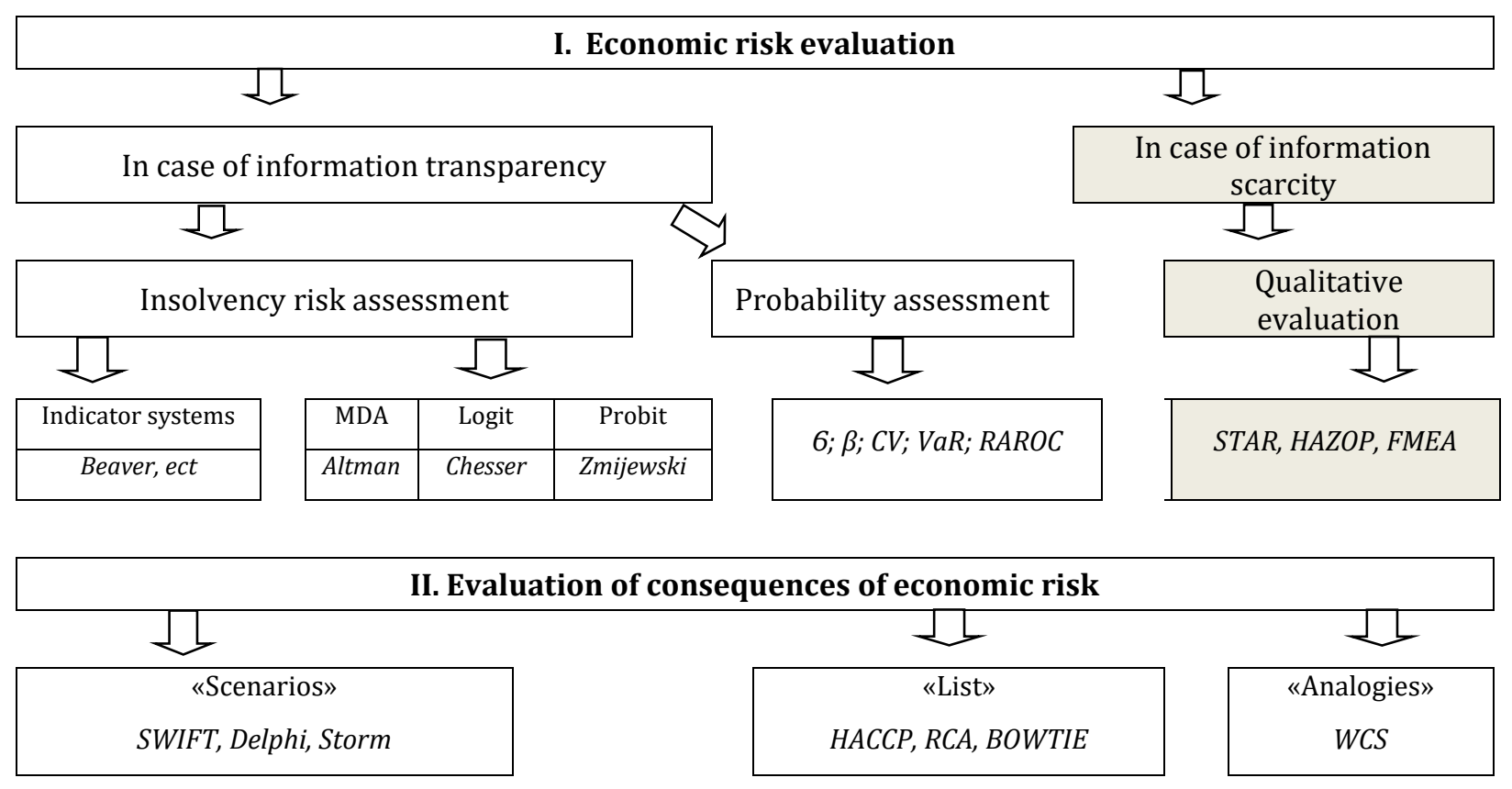

MDA - Multiple Discriminant Analysis; Logit - regression; Probit probit regression; 6 - Standard deviation; $\beta$ - Beta ratio; CV - Coefficient of Variation; VaR - Value at Risk; RAROC - Risk-Adjusted Return on Capital; STAR - Strategic Technology Assessment Review, HAZOP - Hazard and Operability Study; FMEA - Failure Mode and Effects Analysis; SWIFT - Structured What If Technique; HACCP - Hazard Analysis and Critical Control Points; RCA - Root Cause Analysis, WCS Worst Case Scenario.

Figure 1 Concept of evaluating business economic risk

The peculiarity of the authors' concept the concept used in this study is that it included assessment not only in the context of accessible and relatively transparent information but also in the presence of significant information asymmetry. As it is shown, the first group of approaches was made up of risk assessment techniques based on statis-tical analyses. The alternative group included qualitative assessment techniques.

From our point of view, 'scenario', 'list', and 'analogies' techniques, used to assess and anticipate the overall business economic risk, should be considered separately. They are were applied with the estimated probabilities of risk events, which brings us back to statistical techniques. That is, they were not adapted or extrapolated to assess the overall risk, while they were undoubtedly applicable with individual risk events or processes. Therefore, the techniques may be more accurately characterized not as 'economic risk evaluation' but as 'evaluation of conditions and consequences of economic risks'.

\section{Results and Discussion}

\subsection{Business Economic Risk Assessment in the Absence of Information Scarcity}

The algorithm model for evaluating business economic risk in terms of information transparency is summarized by the following steps. The market sector is defined and statistical sampling of insolvent and wealthy enterprise reports is formed. The indicators used for the assessment are defined and based on the selected indicators, a regression equation is built. When there is a sufficient level of reliability, the enterprise economic 
health is forecasted and contributes to the selection of indicators that provide the best determination. The obtained results are verified, considering the available information on the onset of financial insolvency.

The theoretical and methodological base of the discussed indicator system should be primarily based on insolvency risk assessment models. Traditional approaches in this field are represented by non-integral systems suggested by Beaver (1966), as well as integral models including multiple discriminant analysis (MDA) models, logit-, and probit-models adopted by Altman (1968), Ohlson (1980), and Zmijewski (1984), respectively.

When it is impossible or ineffective to identify all potential risk events, probabilistic assessment is also applicable. Notably, there is a wide range of corresponding instruments. For instance, Game theory provides a mathematical tool for finding a variety of solutions (Mednikov et al., 2017). It can be supplemented by risk perception patterns (for risk perception factors see e. g.: Sutalaksana et al., 2019). Volatility assessment is focused on measuring bilateral risk. The beta ratio $(\beta)$ is typical for measuring the risk of financial sector investments (Fama, 1976). The Value at Risk (VaR) indicator evaluates risks through losses with a certain probability. In particular, there are three techniques of obtaining VaR: historical, covariance, and the Monte Carlo technique (Holton, 2014).

There are several advantages and disadvantages of each of the probabilistic indicators. Probability provides the mathematical expectation of the result, but the assessment is often too complicated due to its statistical basis. Standard deviation is easy to calculate, but the dispersion analysis implies complex calculations and requires an understanding of the process under study behavior (whether significant derivation is acceptable or not). Volatility and variation are easily calculated on small samples but are difficult to interpret in terms of risk. The Beta indicator is easy to interpret, as a high value means high profitability and risk, but it is typical for the financial sector. VaR is also evident since it implies a direct account of the risk, but it is only applicable for the known risks and a statistical basis is required. The advantage of the RAROC technique is that it considers a potential income decline when the risk event occurs, but this technique is typical for the banking sector, and is applied to well-studied risks.

Notably, the development and application of insolvency forecasting techniques in assessing business economic risks are currently inconceivable in the lack of digital skills. This applies not only to machine algorithms but to traditional approaches as well. Many Russian companies tend to apply modern management models, including risk assessment (positive results do exist), but in general, their implementation is difficult due to a possible lack of understanding of the need for new effective methodologies and digital transformation (Balashova and Gromova, 2017). At the same time, Russian Fintech developers are among the most competent in the world. Experts expect them to create leading products for international markets (Rudskaya et al., 2018).

Digital implementation of statistical and probabilistic studies, represented by MATLAB, STATISTICA, Prognoz Platform, and similar complexes, simplify computations related to simulation, forecasting, assessment of probabilities, and deviations. Their peculiarity is in high user training requirements. However, these software products may significantly save resources when processing data that requires more complicated computations than basic mathematics.

\subsection{Business Economic Risk Assessment in the Context of Information Scarcity}

This direction implies qualitative assessments based on available statistics on risk events and expert assessment. Initially, these techniques involve risk evaluation in production systems, but by drawing an analogy between failures in technical process and 
financial relations (e.g., debtor payments, loans, cash flows, and income reductions, among others), they are also applicable for assessing economic risks.

The Strategic Technology Assessment Review technique (STAR) assumes expert selection of risk factors, such as expected returns Then, expert assessment of its importance and value is carried out for each factor (Davis et al., 2001). Risk evaluation (RL) in this case will be $R L=I * V$ (Table 1$)$.

Table 1 Strategic Technology Assessment Review (STAR) technique realization

\begin{tabular}{cccc}
\hline \multicolumn{2}{c}{ Importance of the risk factor (I) } & Value of the risk factor (V) \\
\hline & & No risk & $0-1$ \\
Not important & 0 & Low risk probability & $2-4$ \\
$\ldots$ & & Uncertainty & 5 \\
Entirely actual & 1 & Confidence in risk & $6-8$ \\
& & High risk & $9-10$ \\
\hline
\end{tabular}

In addition, the Hazard and Operability Study technique (HAZOP) should be mentioned. It involves an expert search for predictable deviations or undesirable events. The threat probability and severity are expertly assessed for each event (Crawley and Tyler, 2015). Risk assessment (RL) in this case is: $R L=P * H * C$ (Table 2).

Table 2 Hazard and Operability Study (HAZOP) technique realization

\begin{tabular}{lllllc}
\hline \multicolumn{1}{c}{ Threat probability (P) } & \multicolumn{1}{c}{$\begin{array}{c}\text { Worst-case scenario } \\
\text { probability (H) }\end{array}$} & \multicolumn{2}{c}{ Significance (C) } \\
\hline $\begin{array}{l}\text { Very rare (less than 1 time in 100 } \\
\text { observations) }\end{array}$ & 1 & $\begin{array}{l}\text { Very low } \\
\text { (less than 1 in 1,000) }\end{array}$ & 1 & $\begin{array}{l}\text { Low (no or minimal } \\
\text { losses) }\end{array}$ & 1 \\
\hline $\begin{array}{l}\text { Rare (no more than 1 time in 10, at } \\
\text { least 1 in 100 observations) }\end{array}$ & 2 & $\begin{array}{l}\text { Low } \\
\text { (less than 1 in 100) }\end{array}$ & 2 & Significant (losses) & 2 \\
\hline $\begin{array}{l}\text { Probable (no more than 1 time in 1, } \\
\text { at least 1 in 10 observations) }\end{array}$ & 3 & $\begin{array}{l}\text { Significant } \\
\text { (less than 1 in 10) }\end{array}$ & 3 & High (losses) & 3 \\
\hline $\begin{array}{l}\text { Often (more than 1 time per } \\
\text { observation) }\end{array}$ & 4 & $\begin{array}{l}\text { High } \\
\text { (more than 1 in 10) }\end{array}$ & 4 & $\begin{array}{l}\text { Very high (critical } \\
\text { losses) }\end{array}$ & 4 \\
\hline
\end{tabular}

One more related technique is the Failure Mode and Effects Analysis technique (FMEA), which is the tool to reduce negative effects. The FMEA distinctive feature is application of the existing standards that define characteristics of the object and, therefore, the presence or absence of deviations from the required standards (Povolotskaya and Mach, 2012). The risk level is: $R L=S * I * O$ (Table 3).

Table 3 Failure Mode and Effects Analysis (FMEA) technique realization

\begin{tabular}{|c|c|c|c|c|c|c|c|}
\hline \multicolumn{2}{|c|}{ Risk importance (S) } & \multicolumn{3}{|c|}{ Risk impact / Exceeding reserves (I) } & \multicolumn{3}{|c|}{ Risk occurrence $(\mathrm{O})$} \\
\hline Missing & 1 & Missing & No real impact & 1 & 冚 & Negligible & 1 \\
\hline Very insignificant & 2 & Insignificant & $\begin{array}{l}\text { Insignificant reserve } \\
\text { use }\end{array}$ & 2 & \multirow{2}{*}{ 3. } & Envisaged & 2 \\
\hline Insignificant & 3 & Acceptable & Average reserve use & 3 & & Minimal & 3 \\
\hline Very low & 4 & Very low & $\begin{array}{l}\text { Significant reserve } \\
\text { use }\end{array}$ & 4 & \multirow{3}{*}{$\begin{array}{l}\frac{0}{\pi} \\
\frac{\pi}{0} \\
\frac{0}{0} \\
\Sigma\end{array}$} & Rare & 4 \\
\hline Low & 5 & Low & Exceeded by $5-10 \%$ & 5 & & Moderate & 5 \\
\hline Moderate & 6 & Minimal & Exceeded by $10-20 \%$ & 6 & & Equal chances & 6 \\
\hline Important & 7 & Average & Exceeded by $20-30 \%$ & 7 & 江 & Frequent & 7 \\
\hline
\end{tabular}




\begin{tabular}{|c|c|c|c|c|c|c|c|}
\hline Very important & 8 & Above aver. & Exceeded by $30-40 \%$ & 8 & & High & 8 \\
\hline Dangerous & 9 & High & Exceeded by $50-60 \%$ & 9 & \multirow[b]{2}{*}{ 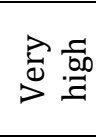 } & Very high & 9 \\
\hline Very dangerous & 10 & Absolute & $\begin{array}{l}\text { High probability of } \\
\text { failure }\end{array}$ & 10 & & Inevitable & 10 \\
\hline
\end{tabular}

Thus, the qualitative risk level assessment suggests summing up all expert assessments. By setting intervals for the final level (RL) relative to the maximum possible (Table 4), decisions may be made. The key moment is to choose the best combination between maximizing results and minimizing risks.

Table 4 Qualitative risk assessment in the face of information scarcity

\begin{tabular}{lc}
\hline Risk level & $\begin{array}{r}\text { Ratio of the estimated level to the } \\
\text { maximum possible (\%) }\end{array}$ \\
\hline Minimal & $0-20$ \\
Low & $20-40$ \\
Moderate & $40-60$ \\
High & $60-80$ \\
Maximal & $80-100$ \\
\hline
\end{tabular}

When it comes to digital solutions that facilitate and enhance the reliability of expert assessments, we noted the enterprises' complex analytical databases. Dun \& Bradstreet (D\&B) is the world's largest registry of private companies (more than 200 million entities). Among the Russian databases, there are SPARK and Contour.Focus, among others. These software products reflect information on registration, reorganization, arbitration proceedings, financial statements, and some calculated financial indices. Their application is justified in forming the idea of business potential, while the task of forecasting is the responsibility of an expert.

\subsection{Risk Evaluation is Assessing Economic Risk Conditions and Consequences}

\subsubsection{Derivatives of the script technique, that is, implying creation of the decision tree}

Brainstorming is a technique of generating ideas in the process of creative dispute and is considered to be the most effective. Employees familiar with the current situation and interested in solving the problem, as well as experts and specialists, may act as experts.

The Delphi technique is targeted at interviewing experts anonymously on the preprepared questions. A multistep expert survey is envisaged. Questions that receive unambiguous assessments are accepted directly, and questions with conflicting answers are processed.

The SWIFT (Structured What If) is sequential process research by a team of experts assessing possible deviations from the projected norm (Maragakis et al., 2009). SWIFT uses structured brainstorming (Card et al., 2012), with pre-designed directional words or headings combined and the expert's clues, which often begin with 'What if ..' phrases (Table 5).

Table 5 Structured What If (SWIFT) technique realization

\begin{tabular}{cc}
\hline Process or system component & Example: current liquidity management \\
\hline Guide & Non-compliance with the standard \\
\hline What if...? / How may...? & Two debtors violate payment terms in parallel \\
Reasons & Incorrect credit risk evaluation \\
\hline Impact & Loss of solvency
\end{tabular}


Risk priority (high / above average / average / below average / low)

Below average

\subsubsection{Creating the risk list}

One of the most popular risk lists is the HACCP (Hazard Analysis and Critical Control Points) technique. Input data is collected by decomposing all elements to build a flowchart, which is followed by identifying potential risk events, as well as actions to prevent them. Then, the control points, in which potential risks may be eliminated or prevented, are identified. After that, a range of parameters is determined for each critical point, which determines the critical boundaries of each point. In addition, control procedures are implemented (HACCP, 2019).

Another technique is to find the root of the problem (RCA: Root Cause Analysis). Its logic is not to study the results and signals of the risk event but its real cause (Wilson et al., 1993). The question for each identified cause is 'Why is it causing the initial problem?'. After each new answer to the question, it is asked over and over again until there are no other answers. Empirically, the number of such iterations is equal to five (AHRQ, 2019).

A feature of the BOWTIE ('Bow Tie') technique is the static nature of the research process. In fact, it is an attempt to give the most complete answer to the only question (process) with respect to all factors that may lead to it, as well as all potential negative outcomes that may result from such a process. It may be assumed that 'Bow Tie' is an RCA interpretation when a certain narrowly focused risk event is investigated. A list of outputs to prevent this risk is created for each possible risk factor. It is proposed to form a list of outputs for each unfavorable outcome, which would help reduce the forced loss-es upon the occurrence of such an event (Bowtie, 2019).

\subsubsection{Analogy technique}

WCS (Worst Case Scenario) is a quite simple and frequent technique. This is the concept of dealing with the worst-case scenario that may be reasonably predicted in a given situation. The worst-case scenario is decided by expert consent. In some cases, the worstcase scenario may be so bad that it is not worth the effort to develop it (Yoe, 2019). Building a business model with only worst-case scenarios in mind forces to plan too conservatively and to spend resources preparing for unlikely circumstances. Organizations that look similar over the given period of time, may differ in the future. It is not always possible to define a similar organization. In the most extreme cases, the use of worst-case scenarios leads to ethical problems.

TWINE, Draw IO, XMind, and other digital products analyze conditions and consequences of economic risks. They help build decision trees, describe possible causes/ consequences/ scenarios, and interconnect elements of any process. Their advantage lies in a friendly interface and in that there is no need for special knowledge and skills. Besides, the initial purpose of such tools is to build visual and detailed diagrams for various purposes, and they are not exclusively specialized in the financial situation research. Thus, the level of research carried out using these digital technologies is determined by the professionalism of experts conducting this qualitative analysis.

\subsection{Advantages and Disadvantages}

Statistical based risk assessment (Indicator and Integral models) is verified and have widespread digital implementation. However, they are applicable only with significant data volumes and still difficult to predict extraordinary flows (for more details, see Lyukevich and Agranov (2019)). The probabilistic assessment gives a quantitative result, but difficulty lies in the need for an informed choice of the estimated indicator. 
The advantages of qualitative assessment lie in the possibility of application in the face of information scarcity or process changes. We also recognized the complexity of strategic and tactical risk factor accounting. Other positive aspects are application of the existing standards (FMEA), highly efficient with the quality control (HACCP), and relative simplicity (HAZOP). However, qualitative techniques are based on the assessment of the risk event onset in terms of taking on risks, which, to some extent, distorts the essence of risk as the event probability. Expert assessment is always subjective, and some risks may not be identified.

Scenario techniques (SWIFT) identify risks in such a way that their results are applicable to quantitative research. However, they are based on subjective expert assessments. The analogy technique is convenient for describing possible risky situations, and less convenient for accurate risk assessment. In this regard, it is important to understand that the worst-case scenario is never the worst-case event. Advantages of the risk list techniques (BOWTIE) are in considering the impact of several optional interrelated events and rather simple result interpretations. The main disadvantage of this group is that only the extreme state (happened or not) should be found for each sub-process (one of the events).

Thus, we formulated an algorithm for choosing a tool for evaluating the business economic risk (Figure 2).

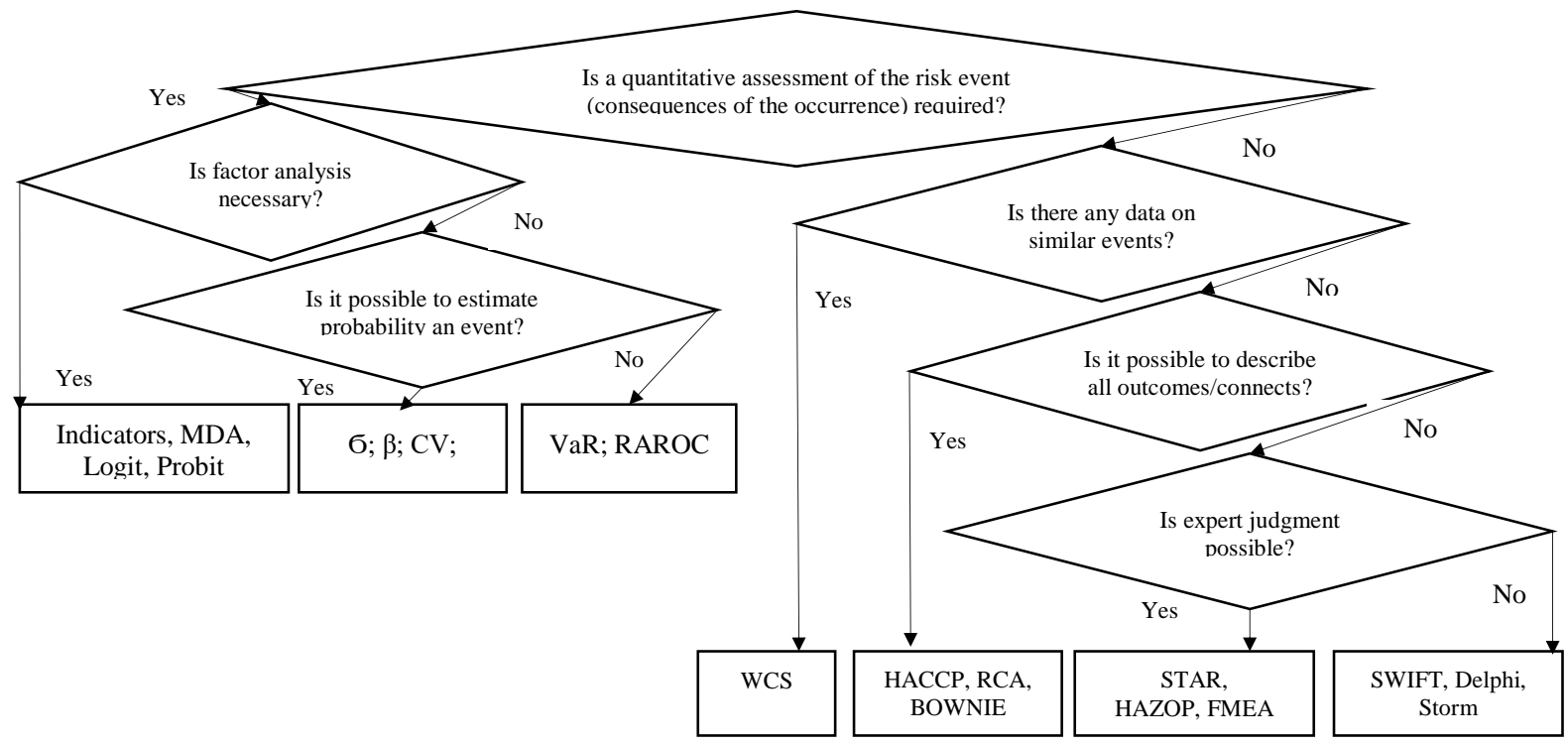

MDA - Multiple Discriminant Analysis; Logit - regression; Probit probit regression; 6 - Standard deviation; $\beta$ - Beta ratio; CV - Coefficient of Variation; VaR - Value at Risk; RAROC - Risk-Adjusted Return on Capital; STAR - Strategic Technology Assessment Review, HAZOP - Hazard and Operability Study; FMEA - Failure Mode and Effects Analysis; SWIFT Structured What If Technique; HACCP - Hazard Analysis and Critical Control Points; RCA - Root Cause Analysis, WCS Worst Case Scenario

Figure 2 Algorithm for choosing a tool for evaluating the business economic risk

\section{Conclusions}

A comprehensive weighty analysis of approaches for evaluating the business economic risk has been carried out. This made it possible to divide the existing approaches into two categories, economic risk evaluation and evaluation of consequences of economic risk, and create a classification of the currently known methods and models for risk evaluation. The peculiarity of this concept is that it includes assessment not only in the context of accessible and relatively transparent information but also in the presence of significant information 
asymmetry. This gives an expanded view of the business economic risk, which is an original solution, compared to other works in the related field.

Systematization of methods and models, in turn, explores the digital experience in each area under consideration. Approaches to the practical implementation of STAR, HAZOP, and FMEA, which are qualitative risk assessment methodologies, are also proposed. Identifying the advantages and disadvantages of methods and models generated the algorithm for choosing a tool for evaluating the business eco-nomic risk.

We agreed that digital experience is currently in progress by means of Industry 4.0 technology (Bataev, 2018; Berawi, 2018), but, at the moment, the main problems of implementation of digitalization are related to national institutional and legal norms, namely to the uncertainty of responsibility (Babkin et al., 2018).

Most statistical models of economic risk assessment involve obtaining reliable results precisely in the areas for which they were created. Therefore, broad extrapolation under basic conditions (e.g., industry, business scale, etc.) leads to an inaccurate result. Unreliability of reporting will also seriously distort the result (e.g., profits overstatement/ understatement, working capital share, etc.). Thus, it seems that logit and probit models may be modified by describing them as a system of inequalities, setting conditions that the sum of the indices should be above / under the normative value. By solving such a system, it is possible to set requirements for financial indicators, which will ensure the formation of broader financial indicators that reflect various risks.

\section{Acknowledgements}

This research work was supported by the Academic Excellence Project 5-100 proposed by Peter the Great St. Petersburg Polytechnic University

\section{References}

Agency for Healthcare Research and Quality (AHRQ), 2019. Root Cause Analysis. Available Online at https://psnet.ahrq.gov/primer/root-cause-analysis, Accessed on July, 25, 2020

Altman, E., 1968. Financial Ratios, Discriminant Analysis and the Prediction of Corporate Bankruptcy. The Journal of Finance, Volume 23(4), pp. 589-609

Arrow, K., 1951. Alternative Approaches to the Theory of Choice in Risk Taking Situation. Econometrica, Volume 19(4), pp. 404-437

Babkin, A.V., Burkaltseva, D.D., Betskov, A.V., Kilyaskhanov, H.S., Tyulin, A.S., Kurianova, I.V., 2018. Automation Digitalization Blockchain: Trends and Implementation Problems. International Journal of Engineering and Technology (UAE), Volume 7(14), pp. 254-260

Balashova, E.S., Gromova, E.A., 2017. Russian Experience of Integrating Modern Management Models. Espacios, Volume 38(53), pp. 31-33

Bataev, A.V., 2018. Analysis and Development the Digital Economy in the World. In: Proceedings of the $31^{\text {st }}$ International Business Information Management Association/ Conference, Volume 1, pp. 61-71

Beaver, W., 1966. Financial Ratios as Predictors of Failure, Empirical Research in Accounting. Journal of Accounting Research, Volume 4, pp. 71-111

Berawi, M.A., 2018. Improving Business Processes through Advanced Technology Development. International Journal of Technology, Volume 9(4), pp. 641-644

Black, F., Scholes, M., 1973. The Pricing of Options and Corporate Liabilities. Journal of Political Economy, Volume 81(3), pp. 637-654 
Bowtie, 2019. Introduction to Bowtie. Available Online at https://www.caa.co.uk/Safetyinitiatives-and-resources/Working-with-industry/Bowtie/AboutBowtie/Introduction-to-bowtie //Accessed on July, 25, 2020

Card, A.J., Ward, J.R., Clarkson, P.J., 2012. Beyond FMEA: The Structured What-if Technique Committee of Sponsoring Organizations of the Treadway Commission (COSO). Internal Control - Integrated Framework. Available Online at https://www.coso.org, Accessed on June, 01,2019

Crawley, F., Tyler, B., 2015. HAZOP: Guide to Best Practice, United Kingdom: Elsevier

Davis, J., Fusfeld, A., Scriven, E., Tritle, G., 2001. Determining a Projects Probability of Success. Research Technology Management, Volume 44(3), pp. 51-57

Demidenko, D.S., Malinin, A.M., Litvinenko, A.N., 2017. A New Classification of the Risks of the Quality Processes. In: Proceedings of the $30^{\text {th }}$ International Business Information Management Association Conference, Volume 1, pp. 147-149

Dvas, G.V., Ivanov, S.A., Dubolazova, Y.A., 2018. Risk Assessment and Risk Management of Innovative Activity of the Enterprise. In: Proceedings of the $31^{\text {st }}$ International Business Information Management Association Conference, Volume 1, pp. 118-119

Fama, E., 1976. Foundations of Finance: Portfolio Decisions and Securities Prices. New York, Basic Books

Gallagher, R., 1956. Risk Management: A New Phase of Cost Control. Harvard Business Review, Volume 34, pp. 75-86

Gissel, J.L., Giacomino, D., Akers, M.D., 2007. A Review of Bankruptcy Prediction Studies: 1930-Present. Accounting Faculty Research and Publications. Available Online at https://epublications.marquette.edu/account_fac/25

HACCP, 2019. HACCP Principles \& Application Guidelines. Executive Summary. Available Online at https://www.fda.gov/food/hazard-analysis-critical-control-pointhaccp/haccp-principles-application-guidelines\#execsum, Accessed on July, 25, 2020

Hidayatno, A., Moeis, A.O., Sutrisno, A., Maulidiah, W., 2015. Risk Impact Analysis on the Investment of Drinking Water Supply System Development using Project Risk Management. International Journal of Technology, Volume 6(5), pp. 894-904

Holton, G., 2014. Value-at-Risk: Theory and Practice. Available Online at https://www.value-at-risk.net, Accessed on July, 25, 2020

Knight, F.H., 1921. Risk, Uncertainty and Profit. Available Online at https://fraser.stlouisfed.org/files/docs/publications/books/risk/riskuncertaintyprof it.pdf, Accessed on July, 25, 2020

Lyukevich, I., Agranov, A., 2019. Correction of Originality in Cash Flow Forecasting to Assess Financial Risk. IOP Conference Series: Materials Science and Engineering, Volume 497(1), pp. 497-499

Malevskaia-Malevich, E.D., Leonov, S.A., Denis, Z., 2018. Methods for Assessing the Effectiveness of Research and Development. In: Proceedings of the $31^{\text {st }}$ International Business Information Management Association Conference. Volume 1, pp. 5886-5890

Maragakis, I., Clark, S., Piers, M., Prior, C.D., Tripaldi, C., Masson, M., Audard, C., 2009. Guidance on Hazards Identification. European Strategic Safety Initiative. Available Online at https://www.easa.europa.eu/sites/default/files/dfu/ECASTSMSWGGuidanceonHazardIdentification1.pdf, Accessed on July, 25, 2020

Mednikov, M.D., Sokolitsyna, N.A., Sokolitsyn, A.S., Semenov V.P., 2017. Game Theory Model of Forming Enterprise Development Strategy in Market Environment Uncertainty. XX IEEE International Conference on Soft Computing and Measurements (SCM), St. Petersburg, Volume 1, pp. 876-878 
Merton, R.C., 1973. The Theory of Rational Option Pricing. The Bell Journal of Economics and Management Science, Volume 4(1), pp. 141-183

Neumann, von J., Morgenstern, 0., 1944. Theory of Games and Economic Behavior: 60 th Anniversary Commemorative Edition Princeton University Press

Nikolova, L.V., Rodionov, D.G., Afanasyeva, N.V., 2017. Impact of Globalization on Innovation Project Risks Estimation. European Research Studies Journal, Volume 20(2), pp. 396410

Ohlson, J., 1980. Financial Ratios and the Probabilistic Prediction of Bankruptcy. Journal of Accounting Research, Volume 18(1), pp. 109-131

Pariaman, H., Garniwa, I., Surjandari, I., Sugiarto, B., 2017. Availability Analysis of the Integrated Maintenance Technique based on Reliability, Risk, and Condition in Power Plants. International Journal of Technology, Volume 8(3), pp. 497-507

Povolotskaya E., Mach P., 2012. FMEA and FTA Analyses of the Adhesive Joining Process using Electrically Conductive Adhesives. ActaPolytechnica, Volume 52(2), pp. 48-55

Rodionov, D.G., Konnikov, E.A., Konnikova, O.A., 2018. Approaches to Ensuring the Sustainability of Industrial Enterprises of Different Technological Levels. The Journal of Social Sciences Research, Volume 3, pp. 277-282

Rudskaya, I., Goncharova, N.L., Temirhanova, M., 2018. Review of the Russian Fintech Market. In: Proceedings of the 31 ${ }^{\text {st }}$ International Business Information Management Association Conference, Volume 1, pp. 2337-2343

Snider, H.W., 1991. Risk Management: A Retrospective View. Risk Management, Volume 38(4), pp. 47-57

Sutalaksana, I.Z., Zakiyah, S.Z.Z., Widyanti, A., 2019. Linking Basic Human Values, Risk Perception, Risk Behavior and Accident Rates: The Road to Occupational Safety. International Journal of Technology, Volume 10(5), pp. 918-929

Taleb, N., 2007. The Black Swan: The Impact of the Highly Improbable. Random House. Published in the United States., New York

Wilson, P.F., Dell, L.D., Anderson, G.F., 1993. Root Cause Analysis: A Tool for Total Quality Management. Milwaukee, Wisconsin: ASQ Quality Press

Yoe, C., 2019. Principles of Risk Analysis: Decision Making Under Uncertainty. Boca Raton: CRC Press

Zmijewski, M.E., 1984. Methodological Issues Related to the Estimation of Financial Distress Prediction Models. Journal of Accounting Research, Volume 22, pp. 59-82 